\title{
EDUCAÇÃO E TRABALHO EM TEMPOS DE PRECARIZAÇÃO
}

\author{
EDUCACIÓN E TRABAJO EN TIEMPOS DE PRECARIZACIÓN
}

\section{EDUCATION AND WORK IN TIMES OF PRECARIOUSNESS}

DOI: http://dx.doi.org/10.9771/gmed.v11i1.27688

\author{
Wagner Pires da Silva ${ }^{1}$ \\ Paulo Henrique Freitas Maciel $^{2}$ \\ Ana Carmita Bezerra de Souza ${ }^{3}$
}

Resumo: A educação é indissociável do trabalho. A relação estreita com o trabalho faz com que a educação se transforme de acordo com as transformações das relações de trabalho. Dessa forma, no sistema capitalista, a educação tem assumido uma forma cada vez menos relacionada ao desenvolvimento das potencialidades e capacidades do trabalhador e voltada ao desenvolvimento de habilidades instrumentais específicas. A pesquisa a seguir procura situar essa relação entre educação e o trabalho nos diferentes modos de produção, detendo-se a configuração que o modelo assume atualmente, apresentando a necessidade de superação do mesmo para que a educação possa cumprir seu papel, negando as determinações do capital sobre a mesma.

Palavras-chave: Trabalho; Educação profissional; Capitalismo;

Resumen: La educación es indisociable del trabajo. La relación estrecha con el trabajo hace que la educación se transforme de acuerdo con las transformaciones de las relaciones de trabajo. De esta forma, en el sistema capitalista, la educación ha asumido una forma cada vez menos relacionada al desarrollo de las potencialidades y capacidades del trabajador y orientada al desarrollo de habilidades instrumentales específicas. La investigación a continuación busca situar esa relación entre educación y el trabajo en los diferentes modos de producción, deteniéndose la configuración que el modelo asume actualmente, presentando la necesidad de superación del mismo para que la educación pueda cumplir su papel, negando las determinaciones del proceso, capital sobre la misma.

Palabras clave: Trabajo; Educación profesional; el capitalismo;

Abstract: Education is inseparable from work. The close relationship with the work causes that the education becomes transformed according to the transformations of the labor relations. Thus, in the capitalist system, education has assumed a form less and less related to the development of the potentialities and capacities of the worker and focused on the development of specific instrumental abilities. The following research seeks to locate this relation between education and work in the different modes of production, stopping the configuration that the model assumes today, presenting the need to overcome it so that education can fulfill its role, denying the determinations of the capital over it.

Key-words: Work; Professional education; Capitalism;

\section{Introdução}

O capital realizou diversas modificações na educação. Interessada em ampliar a extração de valor a burguesia se empenhou em universalizar a educação e permitir que a classe trabalhadora tivesse acesso a ela, para que o mesmo tivesse conhecimento adequado para desempenhar as atividades exigidas pelo Capital. A contínua ampliação da exploração dos trabalhadores, a precarização das relações de trabalho e a diminuição, por conta do avanço da informática, dos conhecimentos necessários para operar os meios de produção resultaram em relegar a educação em simples capacitação do trabalhador. 
Antunes e Pinto (2017) acreditam que, na atualidade, embora a alienação do trabalhador pareça menor, ela está mais internalizada, pois o trabalhador tem "que se envolver como os objetivos do capital. Ele e ela não são mais 'trabalhador ou trabalhadora', mas definidos como 'colaborador e colaboradora', “consultor e consultora"” (ANTUNES; PINTO, 2017, p. 75). Este trabalho discorre sobre a educação profissional e as suas adaptações para atender ao capital. Para isso, cabe entender a relação entre a educação e o trabalho e por fim os modelos de educação impostos à classe trabalhadora.

\section{Uma ação humana: educar}

Não é possível pensar trabalho e educação de forma separada. Saviani (2007) salienta que a origem da educação está no ato do ser humano transformar, em conjunto com seus semelhantes, a natureza, adequando-a as suas necessidades materiais e espirituais, ou seja, produzindo a sua existência em sociedade e a partir da natureza. A divisão da sociedade em classes não muda a natureza geral do trabalho, mas cria processos educacionais distintos de acordo com a classe social.

A humanidade organiza a produção da sua existência material a partir do trabalho, na interação direta com a natureza, inclusive considerando o próprio ser humano como pertencente a esta natureza, que se desdobra nas outras dimensões da vida em sociedade, como a educação, que nas sociedades chamadas primitivas coincidia com a própria construção da vida em coletividade. $\mathrm{O}$ ato educativo estava em todas as práticas da comunidade, pertencia aos momentos de contato social.

Os homens, a partir da transformação constante da natureza, adaptando-a a suas necessidades, produziam a sua existência e se educavam nesse fazer produtivo. Não havia escolas, mas seguramente acontecia educação nos mais variados espaços onde as pessoas se relacionavam e produziam os seus modos de vida. Assim, o trabalho, nesta determinação de transformar a natureza, modifica tanto a matéria propriamente dita, como o corpo do ser humano, humanizando-o, e constitui-se num ato educativo

Portanto, a produção do homem é, ao mesmo tempo, a formação do homem, isto é, um
processo educativo. A origem da educação coincide, então com a origem do homem
mesmo. Diríamos, pois, que no ponto de partida a relação entre trabalho e educação é
uma relação de identidade. Os homens aprendiam a produzir sua existência no próprio
ato de produzi-la. Eles aprendiam a trabalhar trabalhando. (...) A produção da existência
implica desenvolvimento de formas e conteúdos cuja validade é estabelecida pela
experiência, o que configura um verdadeiro processo de aprendizagem. (SAVIANI, 2007,
p. 154)

Da mesma forma que o trabalho, portanto, a educação: “[...] é um fenômeno social e universal, sendo uma atividade humana necessária ao funcionamento de todas as sociedades [...]. Não há sociedade sem prática educativa e nem prática educativa sem sociedade.” (LIBÂNEO, 1994, p. 16-17). O que pode ser interpretado sem prejuízo de compreensão: não há sociedade sem trabalho, tampouco trabalho sem sociedade.

O aparecimento da propriedade privada coincide com o surgimento da escola como local de ócio produtivo, para os detentores dos meios de produção. A posse privada da terra é que permitiria, à parte proprietária, viver sem trabalhar, ou seja, do ócio, na escola. Mas como conseguiram viver do ócio, sem 
trabalhar? Como salientamos na análise de Marx (1989) a origem de toda a riqueza está no trabalho, de um lado, e da natureza, por outro lado. Para que uma parcela da população possa viver sem trabalhar, faz-se necessário que alguém trabalhe por ela. De acordo com Saviani (2007, p.155) (...) "o controle privado da terra onde os homens vivem coletivamente tornou possível aos proprietários viver do trabalho alheio; do trabalho dos não proprietários que passaram a ter a obrigação de, com o seu trabalho, manterem-se a si mesmos e ao dono da terra, convertido em seu senhor".

A partir deste momento dá-se a separação entre trabalho e educação, rompendo a unidade que se identificava no processo de trabalho e criando, agora, duas modalidades de educação. Uma voltada para os escravos, que continuava se realizando no processo de trabalho. Outra voltada para os proprietários dos meios de produção, que consistia em conhecimentos abstratos da realidade, intelectuais, e também atividades físicas. A escola como instituição separada surge neste momento em que a sociedade se separa em classes sociais antagônicas. Para Saviani (2007, p.155,156):

Estamos, a partir desse momento, diante do processo de institucionalização da educação, correlato do processo de surgimento da sociedade de classes que, por sua vez, tem a ver com o processo de aprofundamento da divisão do trabalho. (...) E é aí que se localiza a origem da escola. A educação dos membros da classe que dispõe de ócio, de lazer, de tempo livre passa a organizar-se na forma escolar, contrapondo-se à educação da maioria, que continua a coincidir com o processo de trabalho.

Esta separação, escola para as classes dominantes e educação no processo de trabalho para as classes dominadas, ocorre em todas as formas sociais em que temos a divisão entre trabalho manual e intelectual. O preparo, nestas funções manuais, se dava na prática diária do trabalho. A escola, como uma instituição separada da sociedade, assume um papel de formar intelectuais, dirigentes, para exercerem a dominação no aparelho de Estado e na produção.

(...) a escola, desde suas origens, foi posta do lado do trabalho intelectual; constituiu-se num instrumento para a preparação dos futuros dirigentes que se exercitavam não apenas nas funções da guerra (liderança militar), mas também nas funções de mando (liderança política), por meio do domínio da arte da palavra e do conhecimento dos fenômenos naturais e das regras de convivência social. (...) Nesses contextos, as funções manuais não exigiam preparo escolar. A formação dos trabalhadores dava-se com o concomitante exercício das respectivas funções. (SAVIANI, 2007, p. 157-158).

A transição da sociedade feudal para a capitalista ocorre com mudanças significativas no modo de organizar a produção da existência material. No feudalismo, embora fosse uma sociedade baseada na exploração de classe, o objetivo da atividade econômica era primeiramente a produção de valores de uso, ou seja, a comunidade produzia para satisfazer suas necessidades vitais, para o consumo imediato.

As forças produtivas eram limitadas produzindo basicamente para a subsistência. No entanto, com o desenvolvimento das forças produtivas e da divisão de trabalho, ocorre a produção de excedentes que passa a ser trocados, levando a uma inversão, (produção para o consumo agora se torna produção com o objetivo de troca), que origina outro modo de organizar a produção, a sociedade capitalista. Segundo Saviani (2007, p.158) "Nessa nova forma social, inversamente ao que ocorria na sociedade feudal, é a troca que determina o consumo. Por isso esse tipo de sociedade é também chamado de sociedade de mercado". 
De uma produção voltada para dentro da comunidade, agora temos uma produção voltada para o mercado. Os laços naturais que uniam os membros da comunidade se dissolvem e surgem outras relações, mediadas pela troca. No capitalismo o trabalhador é proprietário de uma mercadoria, a força de trabalho, e entra em contato com o comprador dessa mercadoria, o capitalista, numa relação contratual em que um é vendedor e o outro comprador. Nesse contexto, há a necessidade que a população em geral tenha alguma educação formal, passando a escola a assumir um papel de generalizar na sociedade a cultura letrada, fonte agora em que se baseia a nova ordem que se instalou como dominante. Conforme Saviani salienta (2007, p.158):

Com isso, o domínio de uma cultura intelectual, cujo componente mais elementar é o alfabeto, impõe-se como exigência generalizada a todos os membros da sociedade. E a escola, sendo o instrumento por excelência para viabilizar o acesso a esse tipo de cultura, é erigida na forma principal, dominante e generalizada de educação. Esse processo assume contornos mais nítidos com a consolidação da nova ordem social propiciada pela indústria moderna no contexto da Revolução Industrial.

O desenvolvimento das forças produtivas do trabalho conduziu a sociedade a uma revolução nas formas de produção, apropriada pelo capital. A introdução da máquina destruiu o saber do artesão. $\mathrm{Na}$ realidade, o que aconteceu foi uma transferência do trabalho intelectual/qualificado do artesão para a máquina, materializando-se nela. De acordo com Saviani (2007, p.158) "os ingredientes intelectuais antes indissociáveis do trabalho manual humano, como ocorria no artesanato, dele destacam-se, indo incorporarse às máquinas." Assim, as operações no processo de produção se limitaram a movimentos simples, sem a necessidade das habilidades do artesão qualificado, que detinha conhecimento de todo o processo produtivo. O que prevaleceu foi a separação entre as atividades manuais e as intelectuais, impossibilitando à maioria dos trabalhadores a produção de saberes (ANTUNES; PINTO, 2017).

Além de atacar o saber/fazer da classe trabalhadora, essa divisão do trabalho fez com que os trabalhadores perdessem controle de parte de suas formas de reprodução social, como apontam Antunes e Pinto (2017). Agora seria o capital que ditaria o que o trabalhador precisaria aprender e o que não. Além disso, diminui o poder de barganha dos trabalhadores, uma vez que por meio de treinamentos rápidos e baratos era possível substituí-los quando necessário.

No contexto de uma sociedade baseada na grande indústria e da vida na cidade, a escola assume o papel de responsável pela socialização dos indivíduos. Ao trabalhador cabe capacitar-se minimamente para poder adaptar-se a nova ordem econômica. A educação assume a função de prover uma qualificação "que promove o desmembramento entre conceito, teoria e reflexão (o trabalho intelectual), de um lado, e prática, aplicação e experimentação (o trabalho manual), de outro" (ANTUNES; PINTO, 2017, p. 79). Basta agora uma formação elementar, geral, que possa, inclusive, formar, moldar o indivíduo para adaptar-se a esta nova sociabilidade do capital.

Ao lado desta formação elementar, persistia a necessidade, no processo produtivo, de funções específicas que exigiam uma formação intelectual maior. O ensino profissional ocupou este espaço, seja dado pela própria empresa ou pelo sistema escolar, mas diretamente ligado à produção. Assim, temos duas formas de ensino: uma voltada para a formação profissional e outra voltada para a formação geral. 
Estas (formação geral), por não estarem diretamente ligadas à produção, tenderam a enfatizar as qualificações gerais (intelectuais) em detrimento da qualificação específica, ao passo que os cursos profissionalizantes, diretamente ligados à produção, enfatizaram os aspectos operacionais vinculados ao exercício de tarefas específicas (intelectuais e manuais) no processo produtivo considerado em sua particularidade. (SAVIANI, 2007, p.159).

Ao contrário do escravismo e feudalismo, em que a escola era somente para a elite dominante, e que os dominados tinham sua aprendizagem no processo produtivo, por meio do trabalho, o capitalismo busca universalizar o ensino, porém...

(...) a educação que a burguesia concebeu e realizou sobre a base do ensino primário comum não passou, nas suas formas mais avançadas, da divisão dos homens em dois grandes campos: aquele das profissões manuais para as quais se requeria uma formação prática limitada à execução de tarefas mais ou menos delimitadas, dispensando-se o domínio dos respectivos fundamentos teóricos; e aquele das profissões intelectuais para as quais se requeria domínio teórico amplo a fim de preparar as elites e representantes da classe dirigente para atuar nos diferentes setores da sociedade. (SAVIANI, 2007, p.159).

Persiste a separação entre uma classe que domina os meios de produção e que tem uma educação para ser dirigente e a classe dos despossuídos dos meios de produção. Todo este processo pode ser considerado como uma usurpação do capitalista ao trabalhador "do conhecimento que detêm sobre o seu trabalho a fim de lhes impor, unilateralmente uma nova forma de organização deste, tendo sempre como horizonte as necessidades da máxima extração de mais-valia” (ANTUNES; PINTO, 2017, p. 21). É a imposição dessa nova forma de organização do trabalho que torna a educação profissional uma necessidade.

\section{Educação profissional}

A educação profissional é responsável por repassar um conhecimento sobre o processo de trabalho, mas sob o domínio do capital, ou seja, numa perspectiva parcial e não integral. A escolha de uma profissão, no capitalismo, por parte do trabalhador, não é uma escolha livre, mas condicionada pelo mercado, que funciona a partir da sua própria lógica. Assim, a escolha de uma profissão, nos limites do capital, deve levar em consideração a oferta de empregos do momento econômico e não a vocação de cada indivíduo.

A questão da formação profissional enfrenta, de início, um problema que é da estrutura da sociedade capitalista e que não se separa desta sociedade: a oferta de trabalhadores supera, a demanda do capital. Como consequência disto, existe uma parcela da população que vende a sua força de trabalho e vive com salários de subsistência e uma parcela que sequer consegue lugar no mercado, não tendo a própria subsistência física garantida. Como observa Braverman (1980, p.326), a relação entre emprego e desemprego é bem próxima.

Desse modo, a massa de emprego não pode ser separada de sua correlata massa de desemprego. Nas condições do capitalismo, o desemprego não é uma aberração, mas parte necessária do mecanismo de trabalho do modo capitalista de produção. É continuamente produzido e absorvido pela energia do próprio processo de acumulação. (...) Essa população excedente relativa, o exército de reserva industrial, assume forma variada na sociedade moderna, inclusive os desempregados; os temporariamente empregados; (...) os exércitos de imigrantes, tanto agrícolas como 
fabris; a população negra com suas taxas extraordinariamente elevadas de desemprego; e as reservas estrangeiras de trabalho. (grifos nossos)

Segundo Braverman (1980) o processo educativo envolve o resgate da noção de totalidade do ato produtivo, perdido com a divisão do trabalho e a introdução da máquina, para todos os trabalhadores e não apenas para uma elite que controla tanto a produção como o Estado. Realizando a análise do capitalismo na década de 1970, Braverman (1980) coloca a educação como um elemento fundamental para a acumulação capitalista e como forma de garantir a própria existência deste sistema produtivo, seja na manutenção da ordemou no consumo. A educação em geral e a profissional em particular atendem a interesses que estão além da formação humana. Esta é um meio e não um fim nesta sociedade do consumo e do lucro.

Em sua crítica, Braverman (1980) resgata o conceito de qualificação profissional que está relacionado à formação que o trabalhador tinha como artesão, nas formações pré-capitalistas. Esta formação era resultado de vários anos de trabalho e vida em comunidade. O conhecimento adquirido a partir de um processo de trabalho em que o ser humano tinha uma participação ativa, desde a concepção do que iria produzir até a escolha dos melhores materiais e da experimentação, foi destruído pelo capitalismo e em seu lugar surge um processo rápido em que os trabalhadores são submetidos a um treinamento de acordo com a profissão que vai exercer. Era um processo formativo que levava tempo. Mas nos padrões capitalista foi reduzido a alguns conhecimentos descontextualizado da realidade técnica e da compreensão da vida em sociedade.

Com o desenvolvimento do modo de produção capitalista, o próprio conceito de qualificação torna-se degradado juntamente com a deterioração do trabalho, e o gabarito pelo qual é medido acanhou-se a tal ponto que hoje o trabalhador é considerado como possuindo uma 'qualificação' se ele ou ela desempenhem funções que exigem uns poucos dias ou semanas de preparo; funções que demandam meses de preparo são consideradas muito exigentes, e função que exija preparo por período de seis meses a um ano, tais como a de programador de computador, inspiram um paroxismo de pavor. (Podemos comparar esta situação com o aprendizado tradicional do ofício, que raramente durava menos de quatro anos e que em geral chegava aos sete.) (BRAVERMAN, 1980, p.375)

O conceito tradicional de qualificação perde sua originalidade com a divisão. Nesta mesma lógica, o trabalhador também perde a dimensão de totalidade. O conhecimento que o trabalhador/artesão tinha do processo produtivo, dos seus materiais e das inovações que derivam do próprio processo de trabalho está perdido. A qualificação não se refere mais a este domínio que o trabalhador tinha do processo, mas apenas à parcialidade de algumas funções.

Para o trabalhador, o conceito de qualificação profissional está ligado tradicionalmente ao domínio do ofício- isto é, a combinação de conhecimento de materiais e processos com as habilidades manuais exigidas para desempenho de determinado ramo da produção. O parcelamento das funções e a reconstrução da produção como um processo coletivo ou social destruíram o conceito tradicional de qualificação e inauguraram apenas um modo para domínio do processo de trabalho a ser feito: mediante e com o conhecimento científico, técnico e de engenharia do trabalho. (BRAVERMAN, 1980, p.374)

Esta perda da qualificação, compreendida a partir do conhecimento do artesão, foi agravada com a introdução da máquina, juntamente com a aplicação sistemática do conhecimento científico, no processo 
produtivo. Com o surgimento da máquina fica evidente a separação entre o ato de executar e de pensar, tornando o trabalhador cada vez mais alheio ao que faz.

Quanto mais a ciência é incorporada no processo de trabalho, tanto menos o trabalhador compreende o processo; quanto mais um complicado produto intelectual se torne a máquina, tanto menos controle e compreensão da máquina tem o trabalhador. Em outras palavras, quanto mais o trabalhador precisa de saber a fim de continuar sendo um ser humano no trabalho, menos ele ou ela conhece. (BRAVERMAN, 1980, p.360)

A efetivação do processo produtivo moderno, nas condições capitalistas, no qual o ser humano torna-se apenas um apêndice da máquina, exige pouco conhecimento, comparado com a formação integral de artesão, no sistema anterior. A educação não se torna desnecessária na sociedade do capital, mas não mantém uma relação com a produção. Agora é necessário formar especialistas em diversas áreas, desde a pesquisa às técnicas de produção, gestão e também especialistas na educação. A educação passaria a basearse "em escolas técnicas ditas 'profissionalizantes', cujo mote era formar os/as estudantes para o trabalho assalariado, ou melhor, formar a força de trabalho para o mercado" (ANTUNES; PINTO, 2017, p. 78).

O conhecimento, oriundo da sinergia do trabalho não foi destruído, mas virou propriedade de uma parte de pessoas que detém os meios de produção. Ao trabalhador é necessária apenas uma formação mínima que permita a sua existência enquanto trabalhador. $O$ trabalho torna-se simples meio de subsistência, num mundo cada vez mais rico de possibilidades materiais criadas pelo próprio trabalho.

Esse sistema é compreendido por seus apologistas como exemplificando a eficiência elevada ao máximo grau; onde um engenheiro pode dirigir cinquenta trabalhadores, argumentam eles, não há necessidade de 'desperdiçar' os recursos da sociedade em educar a todos nos padrões da Engenharia. (...) Esta é a lógica do modo capitalista de produção (...) (que) prefere deixar o trabalhador ignorante a despeito dos anos de escolaridade, e roubar a humanidade do seu direito inato de trabalho consciente e magistral. (BRAVERMAN, 1980, p.377 grifos nossos)

Não existe o interesse de que o trabalhador desenvolva as potencialidades. Para o capital, portanto, qualificação é conceito simples e envolve a capacidade do indivíduo trabalhar, mesmo que não compreenda na sua totalidade o que faz.

A perfeita expressão do conceito de qualificação na sociedade capitalista é o que se encontra nos lema estéreis e rudes dos primeiros tayloristas, que descobriram a grande verdade do capitalismo segundo a qual o trabalhador deve tornar-se um instrumento de trabalho nas mãos do capitalista (...) O trabalhador pode continuar uma criatura sem conhecimento ou capacidade, simplesmente uma "mão" pela qual o capital faz o seu trabalho, mas tão logo ele ou ela seja apropriada às necessidades do capital o trabalhador já não mais pode ser considerado ou chamado não qualificado. (BRAVERMAN, 1980, p.377/378)

Educação profissional, hoje, se trata de cursos direcionados para a demanda do capitalismo e se reduz a cursos que visam ao treinamento rápido para exercer alguma profissão. Não podemos considerar esta 'formação' como algo que qualifique, mas pelo contrário, apenas treina a pessoa para servir a um fim imediato do capital, que como sabemos, pode mudar de uma hora para outra, dependendo das possibilidades de lucro em outra atividade e lugar do mundo.

Dando continuidade a sua análise, Braveman (1980) discute o processo de alongamento dos anos de escolarização efetuado nos EUA. Por trás desta ação vislumbra-se interesses muito mais práticos do que 
a execução de um direito da humanidade. A vida na cidade exige um conhecimento mínimo para compreender os códigos de convivência e socialização e, também, para o consumo capitalista. A escolarização se apresenta, inicialmente, como uma forma que a burguesia encontrou para dominar.

A própria vivência urbana, ocasionada pelo desenvolvimento do capitalismo, fez com que aumentasse os anos de escolaridade, mas isso se dá mais como consequência do capitalismo do que a realização de um direito. Neste contexto, a educação surge como uma forma de investimento, ou seja, é considerada apenas na medida em que contribui para a acumulação de capital. Conforme salienta Braverman (1980, p.372) “ademais, a educação tornou-se uma área imensamente lucrativa de acumulação de capital para a indústria de construção, para os fornecedores de todos os tipos, e para uma multidão de empresas subsidiárias." A escola cumpre, assim, várias funções, principalmente econômicas, e a questão da formação do ser humano e da produção do conhecimento convivem neste meio. Para ampliar os lucros a formação a ser ministrada deve ser breve e com o menor custo possível, para isso,

Expandem-se as estruturas de ensino não presencial, ofertando cursos à distância e sob métodos "tutoriais", atingindo não apenas a formação técnica de caráter esporádico e profissionalizante, mas cursos de graduação, inclusive licenciaturas, e de pós-graduação nas mais diversas áreas (ANTUNES; PINTO, 2017, p. 100).

Aplicam-se nas instituições de ensino, todas as ferramentas de gestão, oriundas do mercado. Transformada em negócio, a educação deixa de ser vista como direito e passa ser vista como prestação de serviços, a ser explorada como outro negócio qualquer.

\section{Um novo modelo}

É preciso atuar sob um novo modelo que possa dar conta de realizar a educação, não como uma simples forma de adequar o trabalhador às necessidades do capital, mas como método de construção coletiva dos próprios trabalhadores.

Braverman (1980) aponta que este processo não é interminável e que, para mudar, somente a partir da participação ativa dos trabalhadores. Nesse sentido, para que a educação envolva os trabalhadores, é necessário a superação dos antagonismos no processo de trabalho entre os que controlam a produção, os capitalistas e seus gerentes, e os trabalhadores, ou seja, entre trabalho intelectual e manual.

Essa educação só pode despertar o interesse e atenção dos trabalhadores quando eles se tornarem os senhores da indústria no sentido verdadeiro, isto é, quando os antagonismos no processo de trabalho entre controladores e trabalhadores, entre concepção e execução, entre trabalho mental e manual forem superados, e quando o processo do trabalho for unificado no corpo coletivo que o executa. (BRAVERMAN, 1980, p.376)

Romper com essa estrutura do capital requer uma atitude de mudança não apenas formal, em que trabalhadores votam em diretores ou decidem sobre os processos produtivos, a partir de determinações superiores que já vêm prontas e são legitimadas pelo voto dos trabalhadores. Para Braverman (1980, p.376) esta forma de participação não contribui para que se possa ter uma educação integral. É necessário mais que isso para uma efetiva participação dos trabalhadores nas decisões. 
O conhecimento surge como elemento fundamental para que se efetivem mudanças na concepção de educação. É preciso, apontam Antunes e Pinto (2017, p. 107) “conceber a educação fora dos marcos da separação ente trabalho intelectual e trabalho manual". Trata-se de lutar para que os trabalhadores acessem tanto o conhecimento propriamente técnico do trabalho como os determinantes históricos de formação da sociedade.

A questão educacional está ligada ao modo de produzir a nossa existência material. Dessa forma, criticar a forma como está organizada a produção permite identificar elementos de saída. A superação deste modo de produzir parece ser o caminho para que se tenha uma educação voltada para o aspecto qualitativo de ser humano. Uma educação, no dizer de Gramsci, desinteressada, que desenvolva o caráter e não force o estudante a trilhar apenas pelos caminhos que lhe foram pré-fixados (ANTUNES; PINTO, 2017).

Uma educação que contribua para a superação do capital. Uma educação que possibilite a elevação da classe trabalhadora. Uma educação que forme seres humanos em toda a sua plenitude e não apêndices para máquinas.

\section{Referências}

ANTUNES, Ricardo. Da pragmática da especialização fragmentada à pragmática da liofilização flexibilizada: as formas da educação no modo de produção capitalista. Germinal: Marxismo e Educação em Debate, Salvador, v. 1, n. 1, p. 25-33, mar. 2009. ISSN 2175-5604. Disponível em:

<https://portalseer.ufba.br/index.php/revistagerminal/article/view/9834>. Acesso em: 01 Set. 2019.

ANTUNES, Ricardo; PINTO, Geraldo Augusto. A fábrica da educação: da especialização taylorista à flexibilização toyotista. São Paulo: Cortez, 2017.

BRAVERMAN, H. Trabalho e capital monopolista: a degradação do trabalho no século XX. Rio de Janeiro: Zahjar, 1980.

LIBÂNEO, José Carlos. Didática. São Paulo: Cortez, 1994. (Coleção Magistério 2º Grau/ Série Formação de Professor).

MARX, Karl. O capital: crítica da economia política. São Paulo: Abril Cultural, 1993.

MARX, Karl. O Capital: crítica da economia política. Vol. I, Livro I - O processo de produção do Capital. 13. ed. Rio de Janeiro: Bertraud do Brasil, 1989.

SAVIANI, Dermeval. Trabalho e educação: fundamentos ontológicos e históricos. In: Revista Brasileira de Educação v. 12 n. 34 jan./abr. 2007

\footnotetext{
Notas:

1 Administrador na UFCA. Mestre em Políticas Públicas e Gestão da Educação Superior pela UFC. ORCID: http://orcid.org/00000002-7229-0655. E-mail: wagner.pires@ufca.edu.br

2 Universidade Federal do Ceará. ORCID: http://orcid.org/0000-0002-7106-1842 Email: paulo.freitas@ufca.edu.br

3 Universidade Federal do Cariri. ORCID: http://orcid.org/0000-0001-9368-2052 Email: ana-carmita.souza@ufca.edu.br
} 